\title{
Penilaian Indeks Kinerja Sarana dan Prasarana Daerah Irigasi Seberang Gunung
}

\author{
Kiky Yahdita ${ }^{1}$, Siswanto ${ }^{2}$, Manyuk Fauzi ${ }^{3}$ \\ ${ }_{1,2,3}$ Program Studi Teknik Sipil, Fakultas Teknik, Universitas Riau \\ Kampus Bina Widya Jl. HR Soebrantas KM 12,5 Pekanbaru, Kode Pos 28293 \\ Email: kiky.yahdita@student.unri.ac.id, wantosis702@yahoo.co.id, manyuk.fauzi@unri.ac.id
}

\begin{abstract}
ABSTRAK
Jaringan air irigasi dikelola secara terpadu dari hulu (upstream) hingga hilir (downstream). Kerusakan sarana dan prasarana jaringan irigasi dapat menurunkaan kinerja sistem pengelolaan air irigasi. Penurunan kinerja sistem irigasi mempengaruhi ketersediaan air yang dibutuhkan tanaman padi di sawah dalam satu satuan luas. Penelitian dilakukan untuk menilai kinerja jaringan irigasi Seberang Gunung berdasarkan Peraturan Menteri Pekerjaan Umum dan Perumahan Rakyat Nomor 12/PRT/M/2015 Tahun 2015 dengan menggunakan Indeks Kinerja Sistem Irigasi (IKSI). Parameter penilaian yang digunakan antara lain prasarana fisik, produktivitas tanam, sarana penunjang, organisasi personalia, dokumentasi dan, Perkumpulan Petani Pemakai Air (P3A). Hasil yang diperoleh yaitu kinerja sarana dan prasarana jaringan irigasi Seberang Gunung sebesar $65 \%$. Kinerja jaringan irigasi Seberang gunung termasuk kategori yang kuran, sehingga perlu diperhatikan berdasarkan Permen PU No.12/PRT/M/2015.
\end{abstract}

Kata Kunci: Jaringann irigasi Seberang Gunung, Indeks Kinerja Sistem Irigasi (IKSI), Permen PU No.12/PRT/M/2015.

\begin{abstract}
The irrigation water network was managed in an integrated manner from upstream to downstream. The damage to irrigation network facilities and infrastructure could reduce the performance of irrigation water management systems. The decrease in the performance of the irrigation system could affect the availability of water needed by rice plants in a single unit area of the filed. The research was conducted to assess the performance of the Seberang Gunung irrigation network based on the Minister of Public Works and Public Housing Regulation No. 12/PRT/M/2015 using the Irrigation System Performance Index (ISPI). Irrigation system performance evaluation parameters included physical infrastructure, planting productivity, supporting facilities, personnel organizations, documentation and, Water User Farmers' Association (P3A). The result was obtained that the performance of facilities and infrastructure of the Seberang Gunung irrigation network was $65 \%$. The performance of the Seberang Gunung irrigation network was lacking and needed attention based on PU Ministerial Regulation No.12/PRT/M/2015.
\end{abstract}

Keywords: Seberang Gunung irrigation network, Irrigation System Performance Index (ISPI), PU Ministerial Regulation No.12/PRT/M/2015 


\section{PENDAHULUAN}

Indonesia, sebagai negara agraris, merupakan negara yang melakukan penghidupan melalui sektor pertanian dan perkebunan. Kedua sektor tersebut sangat bergantung dengan ketersediaan air di suatu daerah[4]. Tanaman padi merupakan tanaman pokok dalam sistem pertanian Indonesia yang membutuhkan banyak air dalam penanamannya khususnya pada saat pertumbuhan yang harus selalu tergenangi air. Oleh karena itu, ketersediaan air ang cukup melalui irigasi diperlukan untuk produktivitas padi yang optimal.

Peraturan Menteri Pekerjaan Umum dan Perumahan Rakyat Nomor 12/PRT/M/2015 tentang Eksploitasi dan Pemeliharaan Jaringan Irigasi menjelaskan bahwa irigasi merupakan usaha penyediaan, pengaturan, dan pembuangan air untuk menunjang pertanian. Jaringan irigasi adalah satu kesatuan yang terdiri atas saluran, bangunan, dan bangunan pelengkap yang digunakan untuk penyediaan, pembagian, pemberian, penggunaan dan pembuangan air irigasi[3].

Penetapan sistem pengelolaan irigasi dilaksanakan dengan memperhatikan secara teknis kondisi topografi, tata guna lahan, tata letak outlet, dan jaringan[2]. Sarana dan prasarana yang memadai diperlukan untuk mengelola air irigasi secara menyeluruh. Sarana dan prasarana yang digunakan antara lain bendungan, bendung, saluran primer dan sekunder, kotak (box) bagi, bangunan-bangunan ukur, saluran tersier, dan saluran Tingkat Usaha Tani (TUT). Rusaknya salah satu bangunan irigasi dapat mempengaruhi kinerja sistem, sehingga efisiensi dan efektifitas irigasi pun menurun.

Penelitian dilakukan di salah satu kabupaten Provinsi Riau yaitu di Kabupaten Kuantan Singingi. Daerah irigasi yang dipilih yaitu daerah irigasi Seberang Gunung dengan sumber air yang berasal dari Sungai Omuak. Daerah irigasi Seberang Gunung memiliki luas sebesar 581 Ha yang dibangun pada tahun 1984 dan daerah irigasi tersebut tidak pernah mengalami kerusakan yang serius.

Meskipun sudah memiliki sumber air tersendiri, permasalahann yang dapat menghambat operasional pengelolaann jaringan irigasi tentu pernah terjadi. Operasi pemeliharaan yang belum terpenuhi sebagaimana yang diharapkan dapat mengakibatkan perencanaan fisik maupun perencanaan operasi dan pemeliharaan jaringan irigasi belum efektif. Oleh karena itu, penilaian indeks kinerja perlu dilakukan untuk menganalisa kinerja sarana dan prasarana pada daerah irigasi tersebut. Analisis penilaian kinerja sarana dan prasarana daerah irigasi Seberang Gunung menngacu Peraturan Menteri Pekerjaan Umum dan Perumahan Rakyat Nomor 12/PRT/M/2015 tentang Eksploitasi dan Pemeliharaan Jaringan Irigasi.

\section{METODE PENELITIAN}

\section{Umum}

Metode yang digunakan pada penelitian ini adalah metode yang mengacu pada Peraturan Menteri Pekerjaan Umum Nomor 12/PRT/M/2015 dengan melakukan survey lapangan ke daerah irigasi Seberang Gunung. Metode ini penelitian menjelaskan mengenai metodologi dan langkah-langkah dalam penelitian, yaitu sebagai berikut:

\section{Studi Literatur}

Studi literatur berupa pembelajaran mengenai hal-hal yang berkaitan dengan Operasi Pemeliharaan, terutama Operasi Pemeliharaan Daerah Irigasi Seberang Gunung Kabupaten Kuantan Singingi. Medianya dapat berupa buku, tesis, jurnal, artikel, dan paper.

\section{Lokasi Penelitian}

Lokasi penelitiaan di Kabupaten Kuantan Singingi pada posisi $0^{\circ} \mathrm{LU}-1^{\circ} \mathrm{LS}$ dan $101^{\circ} 02^{\prime}-$ $101^{\circ} 55^{\prime}$ BT, tepatnya di Desa Seberang Gunung, Kecamatan Gunung Toar[1].

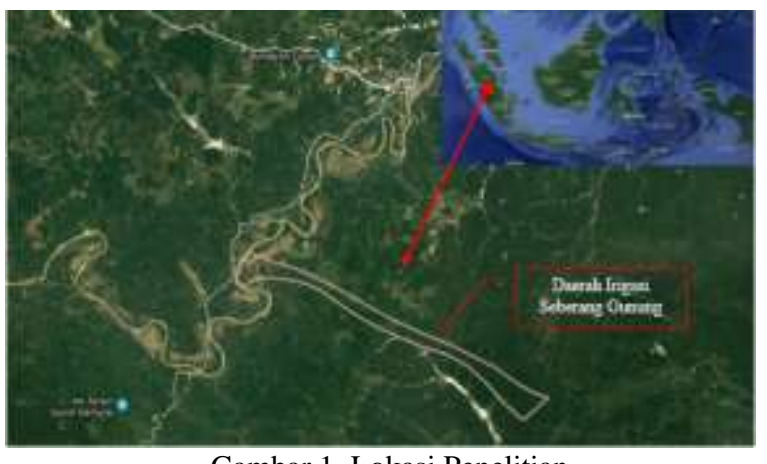

Gambar 1. Lokasi Penelitian

\section{Data Penelitian}

Data primer diperoleh dari hasil pengamatan dan observasi langsung di daerah irigasi Seberang Gunung. Data sekunder yang diperoleh dari Badan Wilayah Sungai (BWS) daerah irigasi Seberang Gunung terdiri dari data klimatologi berupa data temperatur udara, penyinaran matahari, kelembaban udara, dan kecepatan angin; peta jaringan; dan skema bangunan.

\section{Prosedur Penelitian}

Prosedur penelitian yang dilakukan adalah sebagai berikut:

1. Mempelajari lebih rinci terkait penilaian indeks kinerja jaringan irigasi dari berbagai sumber.

2. Mengumpulkan data yang diperlukan yaitu data primer (pengamatan langsung dilapangan) dan 
data sekunder (wawancara dengan pengamat atau P3A) di daerah Seberang Gunung Kecamatan Gunung Toar, Kabupaten Kuantan Singingi.

3. Mengamati kondisi fisik bangunan utama (bendung, pintu kantong lumpur dan pintu penguras), saluran pembawa, bangunan di saluran pembawa, saluran pembuang dan bangunannya, jalan masuk atau inspeksi, kantor, perumaha, dan gudang.

4. Melakukan observasi terhadap produktivitas tanam, sarana penunjang, organisasi personalia, dokumentasi dan kondisi kelembagaan Perkumpulan Petani Pemakai Air (P3A).

5. Menganalisa data primer dan sekunder menggunakan Indeks Kinerja Sistem Irigasi (IKSI) yang mengacu pada Peraturan Menteri Pekerjaan Umum dan Perumahan Rakyat Nomor 12/PRT/M/2015 tentang Eksploitasi dan Pemeliharaan Jaringan Irigasi.

6. Menyusun penilain indeks kinerja terhadap sarana dan prasarana daerah irigasi yang ditinjau secara teknis berdasarkan Undang-Undang ataupun peraturan lain terkait.

\section{Bagan Alir Penelitian}

Untuk lebih jelasnya dapat dilihat pada gambar 1 berikut ini:

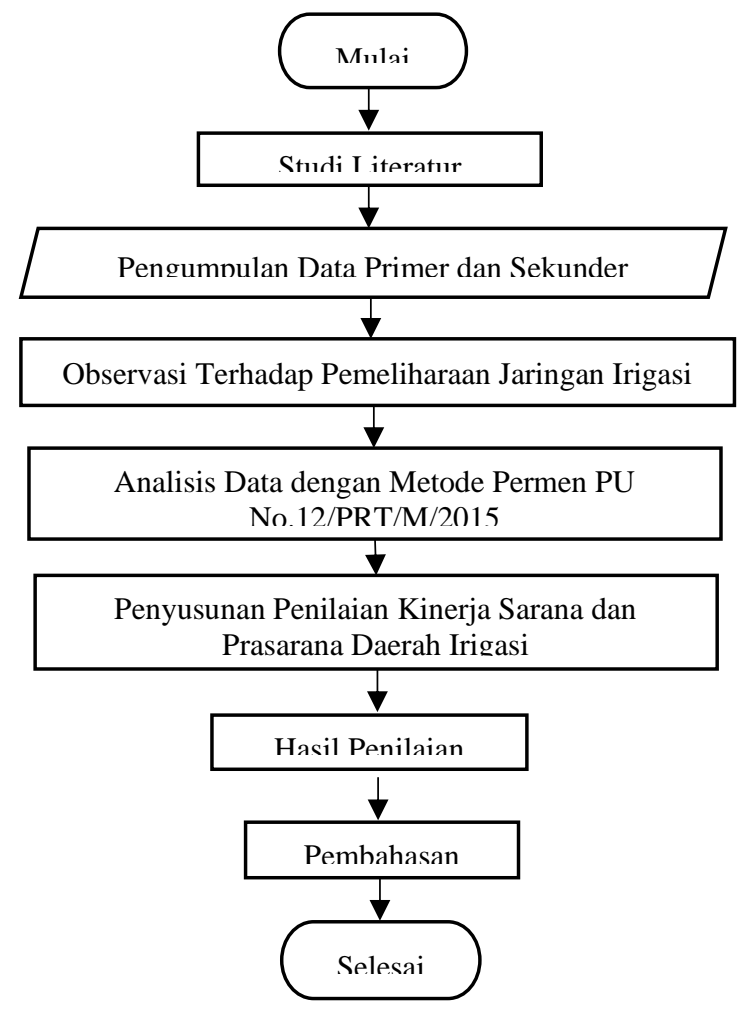

\section{HASIL DAN PEMBAHASAN}

\section{Perhitungan Evapotranspirasi dan Curah Hujan Efektif}

Perhitungan evapotranspirasi (Eto) setiap bulan digunakan persamaan Penman Modifikasi. Perhitungan curah hujan efektif (Reff) dilakukan untuk periode satu tahun. Hasil perhitungannya disajikan pada Tabel 1.

Tabel 1. Hasil Perhitungan Eto dan Reff

\begin{tabular}{|c|c|c|c|}
\hline Bulan & Periode & $\begin{array}{c}\mathrm{Et}_{\mathrm{o}} \\
\text { (mm/bulan) }\end{array}$ & $\begin{array}{c}\mathrm{R}_{\mathrm{eff}} \\
(\mathrm{mm} / \mathrm{hari})\end{array}$ \\
\hline \multirow{2}{*}{ Jan } & I & \multirow{2}{*}{111,862} & 0,86 \\
\hline & II & & 0,53 \\
\hline \multirow{2}{*}{ Feb } & I & \multirow{2}{*}{115,283} & 2,82 \\
\hline & II & & 1,35 \\
\hline \multirow{2}{*}{ Mart } & I & \multirow{2}{*}{106,651} & 3,01 \\
\hline & II & & 1,26 \\
\hline \multirow{2}{*}{ April } & I & \multirow{2}{*}{98,984} & 2,16 \\
\hline & II & & 1,56 \\
\hline \multirow{2}{*}{ Mei } & $\mathrm{I}$ & \multirow{2}{*}{103,154} & 2,87 \\
\hline & II & & 1,94 \\
\hline \multirow{2}{*}{ Juni } & I & \multirow{2}{*}{96,721} & 0,70 \\
\hline & II & & 0,52 \\
\hline \multirow{2}{*}{ Juli } & I & \multirow{2}{*}{98,892} & 0,47 \\
\hline & II & & 0,18 \\
\hline \multirow{2}{*}{ Agus } & I & \multirow{2}{*}{109,297} & 1,33 \\
\hline & II & & 0,28 \\
\hline \multirow{2}{*}{ Sep } & I & \multirow{2}{*}{110,175} & 0,85 \\
\hline & II & & 1,53 \\
\hline \multirow{2}{*}{ Okt } & I & \multirow{2}{*}{120,069} & 2,90 \\
\hline & II & & 0,80 \\
\hline \multirow{2}{*}{ Nov } & I & \multirow{2}{*}{112,165} & 2,22 \\
\hline & II & & 1,57 \\
\hline \multirow{2}{*}{ Des } & I & \multirow{2}{*}{110,615} & 1,82 \\
\hline & II & & 0,05 \\
\hline
\end{tabular}

\section{Analisis Kadar Air Tanah}

Analisis kadar air tanah diperoleh berdasarkan pperhitungan nilai kebutuhan air. Perhitungan nilai kebutuhan air menggunakan nilai perkolasi di Daerah Irigasi Desa Sebrang Gunung sebesar 2,0 mm/hari. Pola tata tanam di Desa Sebrang Gunung adalah Padi-BeraBera. Hasil pehitungan kebutuhan air (NFR) dalam satu tahun disajikan pada Tabel 2.

Tabel 2. Hasil Perhitungan NFR

\begin{tabular}{|c|c|c|}
\hline Bulan & Periode & NFR (lt/dt/ha) \\
\hline \multirow{2}{*}{ Jan } & I & 0,00 \\
\hline & II & 0,00 \\
\hline \multirow{2}{*}{ Feb } & $\mathrm{I}$ & 0,00 \\
\hline & II & 0,00 \\
\hline Maret & I & 0,00 \\
\hline
\end{tabular}


JURNAL TEKNIK - Volume 14, Nomor 1, Edisi April 2020, Halaman 35-43

\begin{tabular}{|c|c|c|}
\hline \hline & II & 0,00 \\
\hline \multirow{2}{*}{ April } & I & 0,00 \\
& II & 0,00 \\
\hline \multirow{2}{*}{ Mei } & I & 0,00 \\
& II & 0,00 \\
\hline \multirow{2}{*}{ Juni } & I & 0,00 \\
& II & 0,00 \\
\hline \multirow{2}{*}{ Juli } & I & 0,00 \\
& II & 0,00 \\
\hline \multirow{2}{*}{ Agus } & I & 0,00 \\
& II & 0,00 \\
\hline \multirow{2}{*}{ Sept } & I & 1,46 \\
& II & 1,36 \\
\hline \multirow{2}{*}{ Okt } & I & 0,58 \\
& II & 0,81 \\
\hline \multirow{2}{*}{ Nov } & I & 0,61 \\
& II & 0,66 \\
\hline \multirow{2}{*}{ Des } & I & 0,22 \\
& II & 0,23 \\
\hline
\end{tabular}

\section{Perhitungan Faktor $K$}

Nilai Faktor $\mathrm{K}$ diperoleh dari perbandingan nilai debit tersedia dan debit kebutuhan[5]. Nilai faktor $\mathrm{K}$ yang telah diperoleh per periode bulan dirata-ratakan sesuai dengan masa tanam, sehingga diperoleh faktor $\mathrm{K}$ dari masa tanam tersebut. Nilai rata-rata faktor K masa tanam 1 di petak sawah daerah irigasi Seberang Gunung diperoleh sebesar 1,00 yang berarti ketersediaan kebutuhan air sudah cukup memenuhi kebutuhan.

Debit tersedia diperoleh dari perkalian antara debit tersedia AWLR (Automatic Water Level Recorder) yang telah diketahui nilainya dengan nilai rasio antara luas DI (Daerah Irigasi) dan luas AWLR (Automatic Water Level Recorder). Hal ini sesuai dengan persamaan (12). AWLR Pulau Berhalo dijadikan sebagai pembanding dalam mencari nilai debit tersedia DI Seberang Gunung. Luas AWLR Pulau Berhalo sebesar $7.467 \mathrm{~km}^{2}$. Luas DI Seberang Gunung sebesar $33,6 \mathrm{~km}^{2}$. Nilai debit tersedia yang diperoleh digunakan untuk menentukan nilai debit andalan $80 \%$. Nilai debit kebutuhan diperoleh dari perkalian antara luas sawah dengan nilai DR (Delivery Requirrement) yang diperoleh dari nilai NFR (Net Field Requirement) dibagi dengan nilai efisiensi sebesar 0,65.

\section{Hasil Penelusuran}

Skema daerah irigasi dan skema bangunan ditunjukkan pada Gambar 3, 4 dan 5.

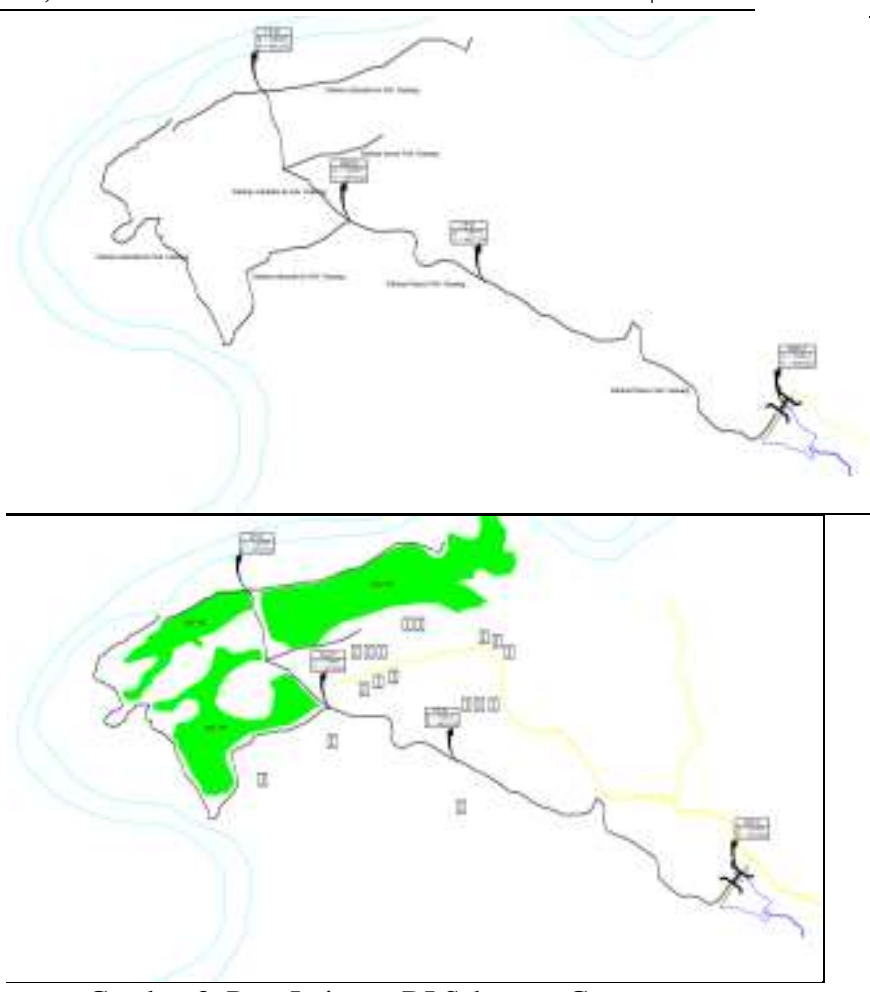

Gambar 3. Peta Jaringan DI Seberang Gunung

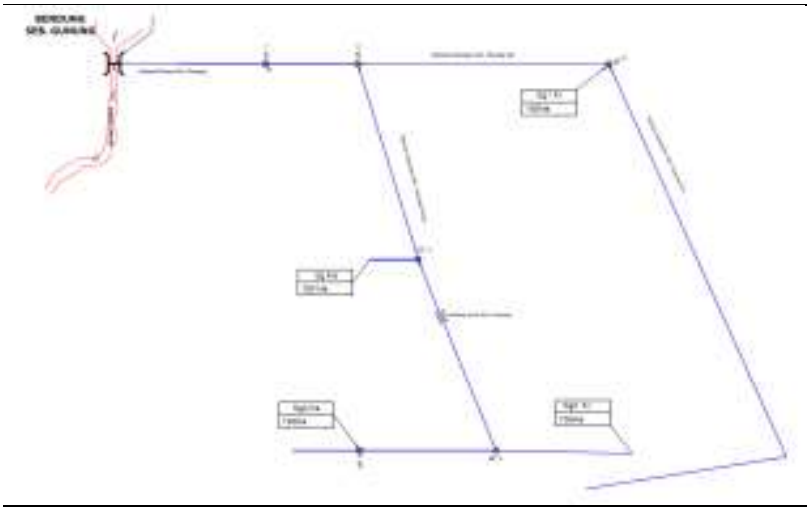

Gambar 4. Skema Irigasi DI Seberang Gunung

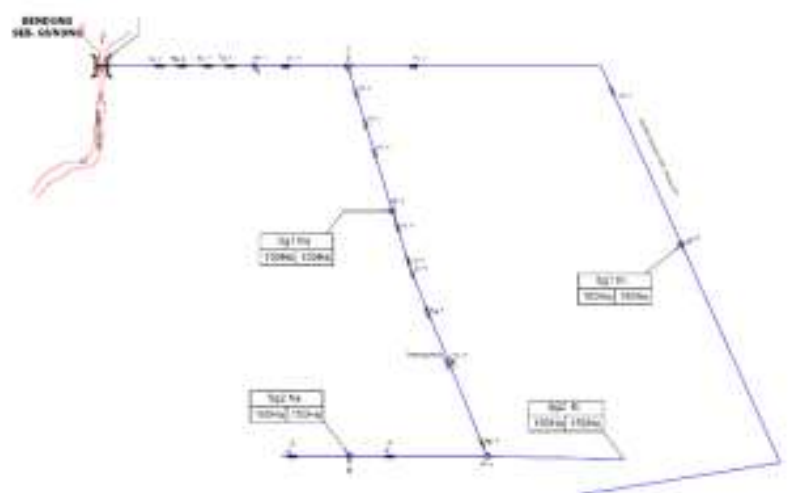

Gambar 5. Skema Bangunan DI Seberang Gunung 
Sistem Daerah Irigasi Seberang Gunung merupakan suatu daerah irigasi yang dilayani oleh satu bending saja. Daerah irigasi Seberang Gunung dialiri oleh sungai omuk yang dibendung oleh bending seberang gunung. Total panjang saluran pada jaringan utama Daerah Irigasi Seberang Gunung untuk saluran pembawa (saluran primer dan saluran sekunder) mencapai 11.275 meter yang mengairi sawah dengan luas 580 ha. Lebih detail hasil penelusuran jaringan irigasi utama di DI Seberang Gunung akan dijelaskan sebagai berikut.

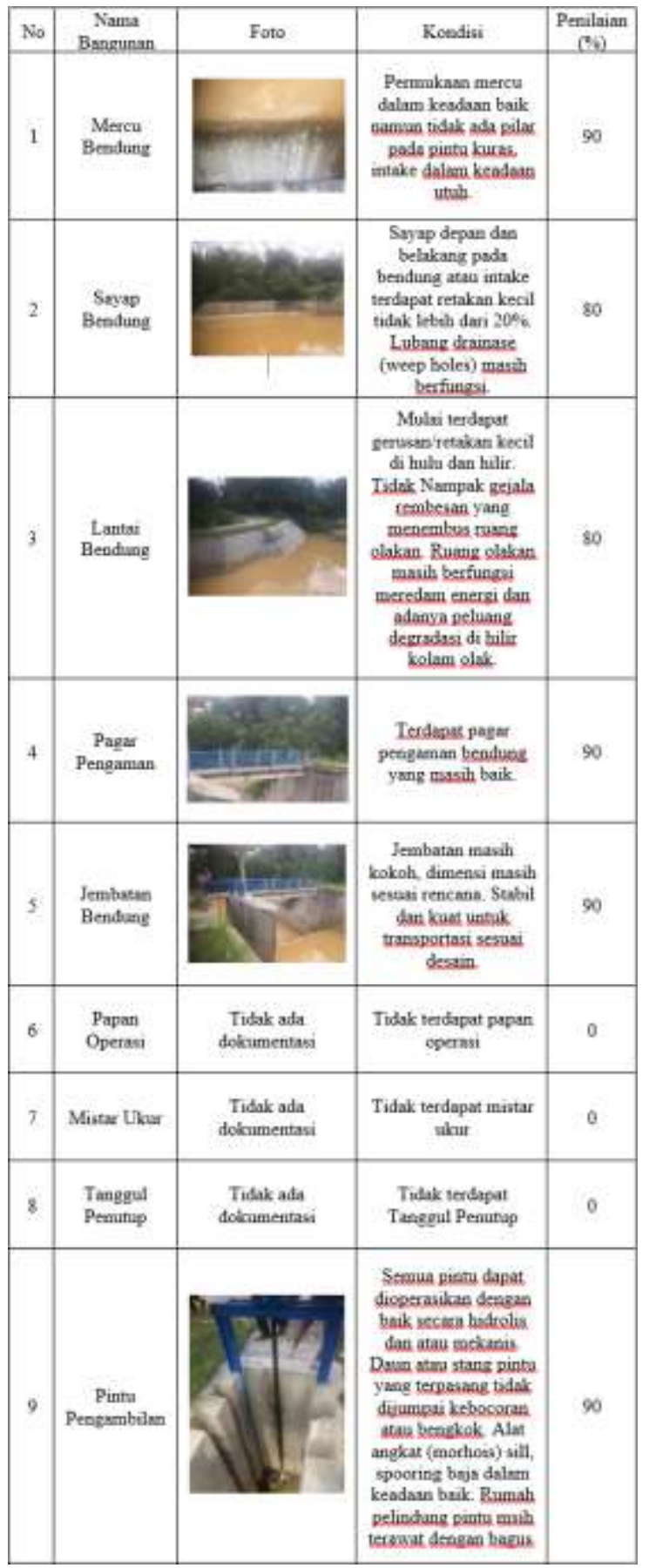

\begin{tabular}{|c|c|c|c|c|}
\hline No & $\begin{array}{c}\text { Nama } \\
\text { Bangusan }\end{array}$ & Foto & Koodisi & $\begin{array}{c}\begin{array}{c}\text { Penilaian } \\
(\%)\end{array} \\
\end{array}$ \\
\hline 10 & $\begin{array}{l}\text { Pintu } \\
\text { Penguras } \\
\text { Bendung }\end{array}$ & & 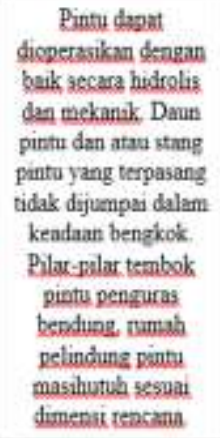 & 90 \\
\hline 11 & $\begin{array}{l}\text { Rapasitas } \\
\text { Saluran } \\
\text { Primer dan } \\
\text { Sekunder }\end{array}$ & & 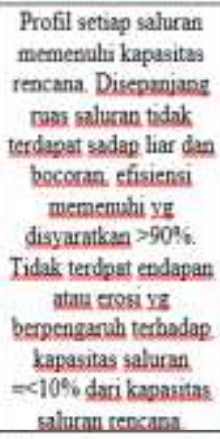 & 90 \\
\hline 12 & $\begin{array}{l}\text { Tinggi } \\
\text { Tanggul }\end{array}$ & & 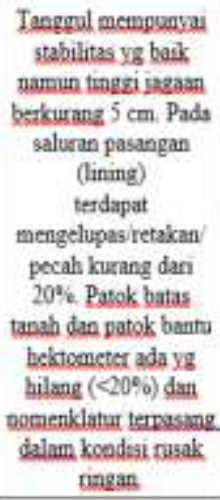 & 80 \\
\hline 13 & $\begin{array}{c}\text { Pelaksanaan } \\
\text { Perbaikan } \\
\text { dan } \\
\text { Pemeliharam } \\
\text { Saluran }\end{array}$ & $\begin{array}{l}\text { Tidak ada } \\
\text { okamentasi }\end{array}$ & $\begin{array}{c}\text { Perbaikan baru } \\
\text { mencapai } 60-<00 \%\end{array}$ & 60 \\
\hline 14 & $\begin{array}{c}\text { Bangunata } \\
\text { Pada Saluran } \\
\text { Pensbawa }\end{array}$ & & $\begin{array}{l}\text { Semua pintu pembagi } \\
\text { dan atau sadap } \\
\text { berfunssi dengza baik } \\
\text { sesara mekanis atau } \\
\text { bidcolis tetapi } \\
\text { fitanami } \\
\text { terumputan remak }\end{array}$ & 90 \\
\hline 15 & $\begin{array}{l}\text { Jalan Masuk } \\
\text { Inspeksi }\end{array}$ & & $\begin{array}{c}\text { Prosentase kondisi } \\
\text { kerusakan di jalan } \\
\text { masuk ke banguann } \\
\text { utama < } 10 \% \text {. } \\
\text { Sebagian kecal } \\
\text { terdarat tanaman liar } \\
\text { tetapi belum } \\
\text { mengsangl }\end{array}$ & 80 \\
\hline
\end{tabular}


JURNAL TEKNIK - Volume 14, Nomor 1, Edisi April 2020, Halaman 35-43

\section{Prasarana Fisik}

Prasarana fisik jaringan irigasi merupakan penunjang utama keberhasilan program irigasi didalam meningkatkan produktivitas tanaman. Didalam Indeks Kinerja Sistem Irigasi (IKSI) disebutkan yang termasuk kedalam prasarana fisik adalah bangunan utama, saluran pembawa, bangunan pada saluran pembawa, saluran pembuang dan bangunannya, jalan masuk/inspeksi dan kantor perumahan dan gudang. Penjelasan yang lebih detail dapat dilihat pada Tabel 3 . Tabel 3. Penilaian Prasarana Fisik DI Seberang Gunung Dari beberapa parameter diatas, didapat bobot final untuk prasarana fisik Daerah Irigasi Seberang Gunung sebesar $27,85 \%$.

\section{Produktivitas Tanaman}

Penilaian terhadap produktivitas tanam di DI Seberang Gunung diperoleh berdasarkan wawancara dengan pihak yang terkait. Wawancara didasarkan kepada Indeks Kinerja Sistem Irigasi (IKSI) sebagaimana terlihat pada Tabel 4 berikut.

Tabel 4. Penilaian produktivitas tanaman DI Seberang

\begin{tabular}{|c|c|c|c|}
\hline \multicolumn{4}{|c|}{ Gunung } \\
\hline No & Uraiso & Kondasi & $\begin{array}{c}\text { Pexulaium } \\
(0,8)\end{array}$ \\
\hline I & $\begin{array}{l}\text { Pemenuhanan keburtuhan } \\
\text { ais ingasi (faktor } K \text { ) }\end{array}$ & $\begin{array}{l}\text { Rata rata faktor } \mathrm{K} \text { pade musium } \\
\text { tanam I sebesar } 0.9 .1\end{array}$ & 100 \\
\hline$\overline{2}$ & Realistsit lass tanam & 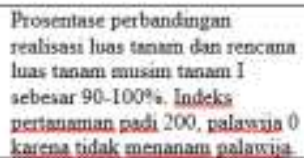 & 33 \\
\hline 3 & Produltivitas padt & $\begin{array}{l}\text { Prosentase pertandingan } \\
\text { realisasi produktivitas pudi dan } \\
\text { rescana produktrivtas padi } \\
\text { masim tanam I sebesar } 90-100 \%\end{array}$ & 48.94 \\
\hline
\end{tabular}

Untuk produktivitas tanam di Daerah Irigasi Seberang Gunung, berdasarkan tiga parameter yang dinilai didapat bobot final sebesar 11,30\%.

\section{Sarana Penunjang}

Sarana penunjang yang akan dinilai dalam evaluasi kinerja sistem irigasi antara lain peralatan operasi dan pemeliharaan, sarana transportasi (sepeda motor pengamat, juru dan PPA), alat kantor pengamat dan alat komunikasi (telepon, handy talkie dan ketersediaan jaringan komunikasi). Untuk lebih jelasnya dapat dilihat pada Tabel 5 .
Tabel 5. Penilaian sarana penunjang DI Seberang Gunung

\begin{tabular}{|c|c|c|c|}
\hline No & Utaim & Kondiat:- & $\begin{array}{c}\text { Retailasas } \\
\text { (\%) }\end{array}$ \\
\hline 1 & $\begin{array}{l}\text { Alat-alat dasar untrik } \\
\text { pemeliharson rutin }\end{array}$ & $\begin{array}{l}\text { Prosentase juminh alat-alat } \\
\text { dasar untuk pemeliharaan rutin } \\
\text { sebesar } 90-100 \% \text { terbadap } \\
\text { jumlah personil lapangan. Alas } \\
\text { dasar dalam kogdisi hak. }\end{array}$ & 90 \\
\hline 2 & $\begin{array}{l}\text { Petlengkapan personil } \\
\text { untuk operasi }\end{array}$ & 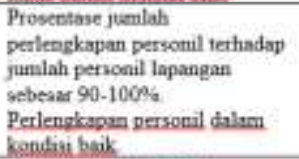 & 90 \\
\hline 3 & $\begin{array}{l}\text { Ketersediaan alat } \\
\text { transortasi untuk } \\
\text { Rasting Pengamat UPID }\end{array}$ & 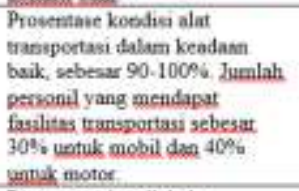 & 100 \\
\hline 4 & $\begin{array}{l}\text { Keternediaan alat } \\
\text { transportasi untuk } \\
\text { Mantri/furu }\end{array}$ & 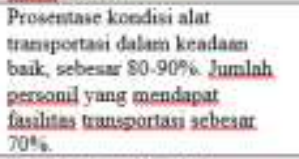 & 100 \\
\hline 5 & $\begin{array}{l}\text { Ketersediaan alat } \\
\text { transportass untuk PPA }\end{array}$ & 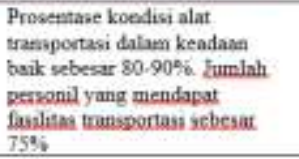 & 80 \\
\hline 6 & $\begin{array}{l}\text { Perabot dasar untuk: } \\
\text { kantor }\end{array}$ & 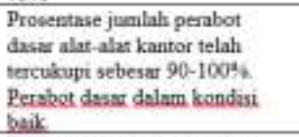 & 90 \\
\hline 7 & Alat kerja di kantor & $\begin{array}{l}\text { Prosentase jumlah alat -alat } \\
\text { kerja di kantor telah tercuikupi } \\
\text { stbeser } 60-79 \%\end{array}$ & 70 \\
\hline 8 & $\begin{array}{l}\text { Ketersediaan Alst } \\
\text { Komuntakasi }\end{array}$ & $\begin{array}{l}\text { Prowensase jumlah alas-alot } \\
\text { komunikasi teiah 1ercukupi } \\
\text { sebesor } 90-100 \% \text {. Alat } \\
\text { kamumikasi dalam keadam } \\
\text { bsik. }\end{array}$ & 100 \\
\hline
\end{tabular}

Berdasarkan beberapa parameter diatas, didapat bobot final untuk sarana penunjang Daerah Irigasi Seberang Gunung sebesar $6,63 \%$.

\section{Organisasi Personalia}

Penilaian organisasi personalia adalah penilaian terhadap struktur organisasi kegiatan Organisasi dan Pemeliharaan (O\&P) berdasarkan tugas dan tanggung jawab, tingkat pemahaman petugas O\&P terhadap tugas dan tanggung jawabnya dan jumlah petugas O\&P yang tersedia. Adapun hasil penilaiannya dapat dilihat pada Tabel 6 berikut. 
Tabel 6. Penilaian organisasi personalia DI Seberang Gunung

\begin{tabular}{|c|c|c|c|}
\hline No & Uraian & Kondisi & $\begin{array}{l}\text { Pentaiam } \\
\text { (Gi) }\end{array}$ \\
\hline L. & $\begin{array}{c}\text { Orgatisasi } \\
\text { Ranting Pengmat UPTD }\end{array}$ & 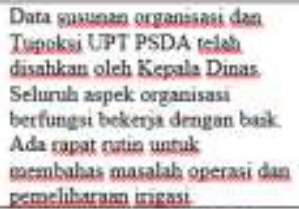 & 100 \\
\hline 2. & Organisasi Mantri/Juru & 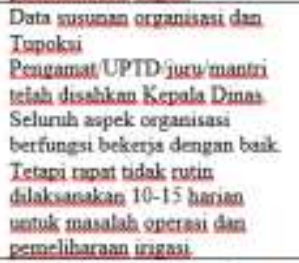 & 90 \\
\hline 3. & Organisasi PPA & 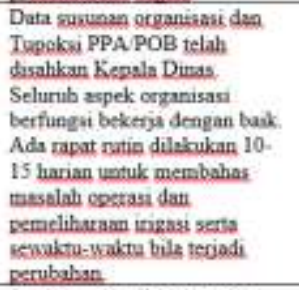 & 100 \\
\hline 4 & Personil Mentri Juns & $\begin{array}{l}\text { Jumlsh persobil sebess } 90 \text {. } \\
100 \% \text { dari yzag dibutihkan. }\end{array}$ & 100 \\
\hline 5. & Personal PPA/POB & $\begin{array}{l}\text { Jumlah yersoeal setbeser } 90- \\
\text { to0\% dari yeng dibuhihkan. }\end{array}$ & 100 \\
\hline 6. & $\begin{array}{l}\text { hunuMantat yang } \\
\text { berstatus Pegansas Neeni } \\
\text { Sipil (PNS) }\end{array}$ & $\begin{array}{l}\text { buru Manta bukan Pegaswa } \\
\text { Negen Suml }\end{array}$ & 0 \\
\hline 6. & $\begin{array}{l}\text { Perscail PPA Pegawai } \\
\text { Negeri Sipil (PNS) }\end{array}$ & $\begin{array}{l}50 \% \text { dari pencoif yateg ada, } \\
\text { sisanya dani tenaga } \\
\text { outsourching }\end{array}$ & 60 \\
\hline 7. & $\begin{array}{c}\text { Pemahaman } \\
\text { Remting Pengamat UPTD } \\
\text { terhadsp Operast dan } \\
\text { Perneliharasn }\end{array}$ & $\begin{array}{l}\text { Hazya } 80-89 \% \text { yang } \\
\text { memahami Operasi dan } \\
\text { Pemeliharsan }\end{array}$ & 80 \\
\hline 7. & $\begin{array}{l}\text { Pentahaman pengelola } \\
\text { ingasi (Juru'Mantri } \\
\text { Pengaina) }\end{array}$ & $\begin{array}{l}\text { Hanyan } 80-90 \% \text { yang } \\
\text { memahami Operasi dan } \\
\text { Pemeliharang }\end{array}$ & 80 \\
\hline
\end{tabular}

Berdasarkan beberapa parameter diatas, didapat bobot final untuk organisasi personalia Daerah Irigasi Seberang Gunung sebesar 10,80\%.

\section{Dokumentasi}

Terdapat beberapa parameter yang dinilai dari data dokumentasi suatu daerah irigasi. Adapun parameter tersebut seperti terlihat pada Tabel 7 berikut.

\begin{tabular}{|c|c|c|c|}
\hline No & Uraian & Kondisi & $\begin{array}{l}\text { Pentaian } \\
\text { (aj) }\end{array}$ \\
\hline 1 & Bulau data DI & 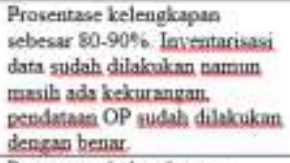 & 80 \\
\hline 2 & Data dindeng di kantor. & $\begin{array}{l}\text { Prosentase kelengkapain } \\
\text { sebesar } 80-90 \% \text { a Kondasi dsta } \\
\text { dindeng di kantor masih balk } \\
\text { tetagi tidak setaua } \\
\text { diverhaharel }\end{array}$ & 80 \\
\hline 3 & Gambar pursalakaania & $\begin{array}{l}\text { Proventrase kelengkapan } \\
\text { selesaf } 90-90 \% \text {. }\end{array}$ & 80 \\
\hline 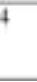 & $\begin{array}{l}\text { Skema DI, skeman } \\
\text { bengunas deat peta } \\
\text { ikhtisar }\end{array}$ & $\begin{array}{l}\text { Prosentase kelengkapan } \\
\text { iebesar } 90-100 \%\end{array}$ & 100 \\
\hline
\end{tabular}

Berdasarkan beberapa parameter diatas, didapat bobot final untuk dokumentasi Daerah Irigasi Seberang Gunung sebesar 4,20\%.

\section{Perkumpulan Petani Pemakai Air (P3A)}

Petani Pemakai Air (P3A) adalah kelembagaan yang ditumbuhkan oleh petani yang mendapat manfaat secara langsung dari pengelolaan air pada jaringan irigasi, air permukaan, embung/dam parit dan air tanah. Adapun parameter yang dinilai dapat dilihat pada Tabel 8 berikut.

Tabel 8. Penilaian Perkumpulan Petani Pemakai Air (P3A) DI Seberang Gunung

\begin{tabular}{|c|c|c|c|}
\hline No & Uraian & Kondisi- & $\begin{array}{l}\text { Penilaian } \\
\text { (s) }\end{array}$ \\
\hline 1 & Stanus GP3AIP3A & Proses peususuman AD/ART & 65 \\
\hline 2 & $\begin{array}{l}\text { Kondisi kelersbaganan } \\
\text { P3A IP3A }\end{array}$ & $\begin{array}{l}\text { Kondrat kelemtagaan P3A } \\
\text { sudah berkembang dengan } \\
\text { prosentave } 30 \% \text {-59\% }\end{array}$ & 70 \\
\hline 3 & $\begin{array}{l}\text { Rapat Ulo-Ulu P3A } \\
\text { Desa/GP3AIP3A dengan } \\
\text { Ranting Pengamat UPID }\end{array}$ & Rapat dilaksanoken berkala. & 75 \\
\hline 4 & $\begin{array}{l}\text { GP3A IP3A aktif } \\
\text { mengikuta } \\
\text { surven penelusuran } \\
\text { jarinsen }\end{array}$ & $\begin{array}{l}\text { Prosentase P3A yane alctif } \\
\text { sebese } 60 \%-79 \% \text {. }\end{array}$ & 70 \\
\hline$s$ & $\begin{array}{l}\text { Partisipasi GP3A.MP3A } \\
\text { dalam perbaikan jaringan } \\
\text { dan pesarganan bencann } \\
\text { dam }\end{array}$ & $\begin{array}{l}\text { Prosentase P3A yang aktuf } \\
\text { sebesar } 60 \% \text {. } 79 \%\end{array}$ & 75 \\
\hline 6 & $\begin{array}{l}\text { Keikutkertaan } \\
\text { GP3A TP3A delam iuran } \\
\text { digunakan untuk } \\
\text { perbaikan jeringan }\end{array}$ & $\begin{array}{l}\text { Prosentase P3A yang ahktif } \\
\text { sebesar } 80 \% 90 \%\end{array}$ & 80 \\
\hline
\end{tabular}

Berdasarkan beberapa parameter diatas, didapat bobot final untuk Perkumpulan Petani Pemakai Air (P3A) Daerah Irigasi Seberang Gunung sebesar 7,63\%.

\section{Penilaian Indeks Kinerja Sistem Irigasi (IKSI)}

Penilaian parameter IKSI dilakukan berdasarkan pengamatan langsung di lapangan dan wawancara dengan pihak yang berwenang di daerah irigasi Seberang Gunung.

Parameter Indeks Kinerja Sistem Irigasi (IKSI) yang memiliki nilai terbesar yaitu prasarana fisik sebesar $45 \%$. Produktivitas tanam, sarana penunjang, organisasi personalia, dokumentasi dan P3A berturutturut memiliki persentase sebesar 15\%,10\%, 15\%, 5\% dan $10 \%$. Prasarana fisik merupakan parameter yang memiliki pengaruh besar terhadap indeks kinerja daerah irigasi, sedangkan dokumentasi adalah parameter yang berperan kecil terhadap indeks kinerja daerah irigasi.

Hasil penilaian parameter kinerja daerah irigasi Seberang Gunung diperoleh sebesar 68,40\%. Nilai kinerja parameter prasarana fisik diperoleh sebesar 27,85\%, produktivitas tanam sebesar 11,30\%, sarana penunjang sebesar $6,63 \%$, organisasi personalia sebesar 10,80\%, dokumentasi sebesar 4,20 \%, dan P3A sebesar 7,63\%. Nilai tingkat kerusakan daerah irigasi diperoleh sebesar 21-40\%, sehingga kinerja sistem irigasi di daerah irigasi Seberang Gunung termasuk 
kategori kurang. Oleh karena itu, daerah irigasi Seberang Gunung memerlukan penanganan dengan cara pemeliharaan berkala yang bersifat perbaikan.

\section{Pembahasan}

Berdasarkan hasil perhitugan curah hujan dan evapotranspirasi, nilai NFR terbesar di daerah irigasi Seberang Gunung terdapat di bulan September periode I sebesar 1,46 lt/dt/ha. Hal ini berarti jumlah air yang dibutuhkan pada daerah irigasi Seberang Gunung adalah 1,46 lt/dt/ha. Oleh karena itu, bendungan daerah irigasi Seberang Gunung harus dapat menyediakan air sebesar nilai tersebut agar kegiatan pertanian tetap berjalan lancar.

Berdasarkan penilaian yang dilakukan, parameter prasarana fisik hanya memperoleh persentase sebesar $27,85 \%$ atau $61,9 \%$ dari persentase maksimum yaitu $45 \%$. Pada prasarana fisik, ada beberapa bangunan yang tidak ada di antaranya papan operasi, mistar ukur, dan tanggul penutup. Apabila item-item tersebut telah dibangun pada daerah irigasi Seberang Gunung, hal tersebut akan menaikkan indeks kinerja sistem irigasi tersebut.

Nilai yang didapatkan untuk item produktivitas tanam sebesar $11,30 \%$ atau $75,33 \%$ dari persentase maksimum yaitu $15 \%$. Persentase ini sudah masuk dalam kategori baik, namun juga harus diperhatikan lagi. Produktivitas padi daerah irigasi Seberang Gunung kurang baik, disebabkan banyaknya hama yang menyerang pada tanaman padi tersebut.

Sarana penunjang daerah irigasi Seberang Gunung memperoleh nilai 6,63\% atau 66,25\% dari persentase maksimum yaitu $10 \%$. Hal yang perlu diperhatikan untuk meningkatkan persentase pada sektor ini yaitu kelengkapan alat untuk Operasi dan Pemeliharaan (O\&P) serta fasilitas yang memadai seperti alat-alat kerja di kantor.

Organisasi personalia memperoleh penilaian sebesar $10,80 \%$ atau $72,00 \%$ dari persentase maksimum yaitu $15 \%$. Pada sektor ini perlu diperhatikan lagi dalam pengelolaannya. Struktur organisasi beserta tugas-tugas harus diperjelas dan setiap orang yang bertanggung jawab telah memahami batasan dan tugasnya masingmasing.

Parameter dokumentasi mendapatkan nilai 4,20\% atau $84 \%$ dari persentasi maksimum yaitu $5 \%$. Hal ini berarti dokumentasi daerah irigasi Seberang Gunung sudah baik. Hal ini dapat dilihat dari adanya peta jaringan dan peta skema bangunan.

Parameter Petani Pemakai Air (P3A) memperoleh nilai $7,63 \%$ atau hanya $76,25 \%$ dari persentase maksimum yaitu $10 \%$. Peran serta petani di daerah irigasi Seberang Gunung perlu ditingkatkan lagi dalam penyelenggaraan sistem irigasi. Salah satunya dengan cara mengadakan rapat minimal satu bulan sekali. Selain itu, partisipasi P3A dalam perbaikan jaringan juga sangat penting untuk meningkatkan penilaian pada parameter ini.

\section{KESIMPULAN DAN SARAN}

\section{Kesimpulan}

Hasil penilaian indeks kinerja sarana dan prasarana daerah irigasi Seberang Gunung dapat disimpulkan, bahwa:

a. Dengan menggunakan data curah hujan tahun 2013 - 2017 dan data klimatologi tahun 2013 2017, nilai kebutuhan air untuk irigasi dengan pola tata tanam padi-bera-bera didapat sebesar 1,46 1/dt/ha.

b. Berdasarkan Peraturan Menteri Pekerjaan Umum dan Perumahan Rakyat No. 12/PRT/M/2015 yang diterjemahkan kedalam Indeks Kinerja Sistem Irigasi (IKSI), nilai indeks daerah irigasi Seberang Gunung didapat sebesar $68,40 \%$. Nilai tersebut termasuk kategori kinerja yang kurang dan perlu perhatian terutama pada produktivitas tanaman.

\section{Saran}

Saran yang dapat diberikan terhadap penelitian selanjutnya yaitu:

a. Pemerintah sebaiknya lebih melengkapi kebutuhan prasarana fisik bendungan daerah irigasi Seberang Gunung seperti mistar ukur, papan operasi, kantong lumpur dan papan penguras agar kinerja dari suatu sistem irigasi meningkat.

b. Pelaksanaan penilaian kinerja sistem irigasi semestinya dilaksanakan secara konsisten setiap tahun.

\section{DAFTAR PUSTAKA}

[1] Google Maps. (n.d.). Retrieved April 03, 2018, from Google Maps: https://www.google.com/maps/search/LOKASI + LINTANG+SEBERANG+GUNUNG+KECA MATAN+GUNUNG+TOAR/@ $0.6429315,101.4924299,12 \mathrm{z} /$ data $=! 3 \mathrm{~m} 1$ !4b1

[2] Fauzi, M., Ari S., Sigit S., dan Suharyanto. (2017). Penilaian Indeks Kinerja Daerah Irigasi Berdasarkan Peraturan Menteri PUPR Nomor 12 Tahun 2015. Konferensi Nasional Teknik Sipil dan Infrastruktur-1. Jember. Retrieved 2019.

[3] Mentri Pekerjaan Umum dan Perumahan Rakyat Republik Indonesia. (2015). Peraturan Mentri Pekerjaan Umum dan Perumahan Rakyat Nomor: 12/PRT/M/2015 Tentang Eksploitasi dan Pemeliharaan Jaringan Irigasi. Mentri Pekerjaan Umum dan Perumahan Rakyat Republik Indonesia. Jakarta. Retrieved 2018. 
[4] Prasetiyo, AR. (2017). Audit Teknis Sebagai Dasar Penyusunan AKNOP Pada Daerah Irigasi Tuk Kuning. Skripsi. Teknik Pengairan Konsentrasi Pengetahuan Dasar Teknik Sumber Daya Air. Malang. Retrieved March 20, 2018.
[5] Putra, YP. (2018). Indeks Kinerja Irigasi Utama Daerah Irigasi Seberang Gunung Kabupaten Kampar. Jurnal Online Mahasiswa (JOM) Bidang Teknik dan Sains 5(1): 1-7. Retrieved 2018 